\title{
Does Baker-Miller pink reduce aggression in prison detention cells? A critical empirical examination
}

\author{
Oliver Genschow $^{\mathrm{a} *}$, Thomas Noll ${ }^{\mathrm{b}}$, Michaela Wänke ${ }^{\mathrm{c}}$ and Robert Gersbach ${ }^{\mathrm{d}}$ \\ ${ }^{a}$ Department of Experimental Psychology, Ghent University, Gent, Belgium; ${ }^{b}$ Swiss Prison Staff \\ Training Center, Fribourg, Switzerland; ' Department of Consumer and Economic Psychology, \\ University of Mannheim, Mannheim, Germany; ${ }^{d}$ Justizvollzugsanstalt Pöschwies, Regensdorf, \\ Switzerland
}

(Received 8 May 2014; accepted 17 October 2014)

\begin{abstract}
Many prisons across Western countries recently began to paint detention cells in Baker-Miller pink to calm down aggressive inmates. This recent development is based on early findings of more than 30 years ago suggesting that Baker-Miller pink reduces physical strength and thus aggressive behavior. In the present study we question the applied methods of the original studies and run a highly standardized and controlled experiment to test the influence of Baker-Miller pink on aggressive behavior. The results do not replicate the original findings and thus challenge the recent adoption in many prisons. Implications and limitations of the experiment are discussed.
\end{abstract}

Keywords: color; aggression; Baker-Miller pink; prison; calming

In 1979, Schauss (see also, Pellegrini, Schauss, \& Miller, 1981) reported that prison inmates calmed down more strongly when they were incarcerated in cells painted in socalled Baker-Miller pink compared to white cells. Baker-Miller pink is a color named for two US Navel officers who first investigated the influence of that specific color. BakerMiller pink was originally produced by mixing one pint of outdoor semi-gloss red trim paint and one gallon of pure white indoor latex paint (cf. Schauss, 1979). Presumably, the visual processing of the Baker-Miller pink affects neurological and endocrine functions, which in turn reduce physical strength, and thus aggressive behavior (cf. Ott, 1979; Pellegrini, Schauss, \& Miller, 1981). Based on this reasoning many prisons across Western countries (for an overview see Table 1) recently began to paint detention and prison cells in Baker-Miller pink to calm down aggressive inmates. In Switzerland, for example, almost every fifth prison or police station has now at least one pink detention cell. But does it really work?

Let's first look at the evidence regarding pink reducing physical strength. In the very first examinations (Schauss, 1979, 1981), participants stretched out their arms and held them at a $90^{\circ}$ angle in front of their bodies while the experimenter tried to press down participants' arms. Participants were instructed to resist the experimenter's pressure as long as possible. In a first trial, a baseline measure of resistance was established. In the second trial, participants were shown a pink card and in the third trial, a blue card. It turned out that participants could resist the pressure less when exposed to the pink

*Corresponding author. Email: oliver.genschow@ugent.be 
Table 1. Overview of pink prison cells in Western countries based on Internet research and European Network Penitentiary Training Academies (EPTA) mailing lists.

\begin{tabular}{|c|c|}
\hline Countries with pink prison cells & Amount $\mathrm{c}^{\mathrm{c}}$ \\
\hline Switzerland ${ }^{\mathrm{a}}$ & $\sim 30$ \\
\hline $\begin{array}{l}\text { USA a including South Carolina, Texas, Arizona, Washington State, Kansas, and } \\
\text { Missouri }\end{array}$ & $>20$ \\
\hline Canada $^{\mathrm{a}}$ & $>5$ \\
\hline Germany $^{\mathrm{a}}$, Poland ${ }^{\mathrm{b}}$ & $>1$ \\
\hline Austria $^{\mathrm{a}, \mathrm{b}}$, England ${ }^{\mathrm{b}}$ & Minimum \\
\hline
\end{tabular}

${ }^{\mathrm{a}}$ Based on Internet research.

${ }^{\mathrm{b}}$ Based on EPTA mailing lists.

${ }^{c}$ Estimates are based on the respective information sources.

compared to the blue cards. In other studies, a dynamometer measured reduced squeeze strength in hands (Pellegrini \& Schauss, 1980) and legs (Pellegrini, Schauss, \& Birk, 1980) when participants were shown a pink compared to a blue card.

Although these experiments suggest a strength reducing effect of the color pink, some methodological concerns do not allow a clear answer of whether pink indeed lowers physical strength. First, in the Schauss $(1979,1981)$ examinations, an effect of the experimenter cannot be ruled out, because the experimenter does not seem to have been blind to the hypothesis and the conditions. Second, order of the color presentation was not counterbalanced. So, order and training effects cannot be ruled out either. Third, the effects of all three studies are rather weak. As Pellegrini and Schauss (1980) admitted: 'Although significant at the $p<.05$ level, the color effect accounted for only about 5 percent of the variance on the dependent measure' (p. 146).

Indeed, several attempts to replicate these early findings failed to find any supportive evidence (e.g., Gilliam \& Unruh, 1988; Pellegrini, Schauss, Kerr, \& You, 1981; Schwartz, Harrop, Love, Marchand, \& Read, 1983). For example, in a methodologically sound experiment, Gilliam and Unruh (1988) exposed participants to white and pink cards and counterbalanced the order of the color presentation. The researchers monitored participant's blood pressure, pulse-rate, grip strength, response speed, visuo-motor coordination and the performance on the Digital-Symbol subset of the Wechsler Adult Intelligence Scales-Revised (WAIS-R; Wechsler, 1981) - a measure for sustained attention. Significant results were only found in the less important Digital-Symbol measure and this result was attributed to learning effects.

Similar to the above-mentioned studies on physical strength, experiments that tested the effect of pink prison cells on aggressive behavior suffer from methodological shortcomings and conflicting results. While the very first evidence of Schauss (1979) is just based on anecdotal evidence, Pellegrini et al. (1981) ran a more systematic study and found less aggressive behavior of inmates in pink, compared to white prison cells. Unfortunately, several shortcomings restrict the interpretation of this finding. First, the authors measured aggressive behavior of inmates in white cells during one year and then aggressive behavior of inmates in pink cells in the subsequent year, thus the manipulation of the color was confounded with time. Although the researchers found support for their hypothesis, the effect might just be due to differences between the two years, because participants were not randomly assigned to the experimental conditions (cf. Campbell, Stanley, \& Gage, 1963; Fisher, 1935). Unfortunately, nothing is known about other 
changes between the two years such as different personnel, leisure activities, background of inmates, and other factors that may have had an influence on the inmates' behavior. Second, based on the reported procedure, it is not apparent whether the coders were blind to the hypothesis. Third, it is noteworthy that the authors also cite evidence of two nonreplications by Snyder (1981) and McDonald (1981). ${ }^{1}$

Based on the conflicting findings in the literature, the rather questionable methods of the studies and the high social relevance of the topic, we sought to shed more light onto the matter by running a better-controlled experiment in a Swiss maximum-security penitentiary.

\section{Method}

\section{Ethics statement}

The ethics committee of the Canton of Zurich, Switzerland approved the procedure and method of the study as well as a contract between the researchers and the staff of the Justizvollzugsanstalt Pöschwies. Based on this contract it was agreed that all involved members of the project are participating voluntarily and are allowed to remove themselves from the project without giving any reason and expecting any negative consequences.

\section{Participants and design}

Inmates of the Justizvollzugsanstalt Pöschwies in Regensdorf (Switzerland), who were placed into detention for several days after violating prison regulations, took part in the experiment. Reasons for detention are, for example, assault, threat, disturbance of order and security, possession of weapons, alcohol and drug abuse. Participants were randomly assigned to one of two conditions: pink versus white detention cell. Due to ethical reasons highly agitated inmates were not included into the experiment. It was assumed that those individuals would profit mostly from the expected effects of the pink detention cell. This positive treatment could only be guaranteed by excluding these persons from the experiment, because otherwise they would also have to be assigned to the control group (white detention cell). In total, four inmates who were too highly agitated were excluded from the study. Sixty-nine inmates who were placed into detention were asked for their consent to participate in the study. Ten of these inmates did not consent. Thus, the final sample of the experiment included 59 male inmates. All of these completed the study. The mean age of the sample was $28.97(S D=7.42)$. The age ranged from 19 to 46 .

\section{Procedure}

Before the onset of the actual experiment, all guards who would possibly come into contact with the inmates were trained how to fill out the questionnaire that was going to be applied in the experiment. First, the questionnaire was extensively studied and all items were explained in detail by the researchers. Second, based on own observations of the last five inmates that were in detention cells, the guards filled out the questionnaires. Afterward, the indications of every guard were compared and discussed in order to calibrate the guards' observations. To ensure the guards' blindness to the hypotheses, the researchers explicitly mentioned that there were different hypotheses regarding the color pink. Some data showed no influence, others showed a decrease in aggression whereas 
yet others showed an increase. Finally, it was stressed that the guards' participation in the project is based on their own choice and that everyone is allowed to quit participation at any time without giving any reason and expecting any negative consequences. All guards agreed to participate and there were no dropouts during the study period. After the training, the actual observation phase began. From 9 January 2012 to 28 July 2013, the guards observed the inmates. The inmates were randomly assigned to the pink or the white detention cell. Four cells, identical in size, were used. From the ceiling, over the walls to the floor two cells were completely painted in Baker-Miller pink (LCh: 72.6317; $44.818 ; 3.4356)$. The other two cells remained in neutral colors. That is the ceiling and the walls were white (LCh: 94.570; 4.167; 83.523) and the floor light gray (LCh: 81.290; $1.470 ; 32.501)$. As soon as an inmate had entered the detention cell, the guard in charge indicated basic demographic data and rated the inmate's aggression level (see below). From this point on, all types of the inmate's aggressive behavior were noted in the questionnaire. After one day in the detention cell, inmates were asked to sign a statement of agreement if they would like to participate in the study. For those who did not consent, the already collected data were destroyed. If participants agreed to participate in the study, they were further observed for the next two days. While all participants stayed at least three days in the detention cell, some had to stay even longer. Therefore, after a total of three days in the detention cell, the guard again rated the aggression level of the inmate and then ended the observation.

\section{Measures \\ Aggression level}

The guards rated the inmates' aggression level as soon as inmates entered the detention cell (first assessment) and after three days staying in the cell (second assessment). Aggression level was rated on nine items on a 7-point scale ranging from 1 (not at all) to 7 (very much). Five items were positively formulated (angry, sore, upset, furious, nervous, thrilled) and three items were negatively formulated (calm, relaxed, composed). To prepare the data for the analyses, we first reversed the negative formulated items and then calculated an average score over all items. High values indicate high levels of aggression. Cronbach's alpha for the first assessment is $\alpha=.93$ and for the second assessment $\alpha=.96$.

\section{Aggressive behavior}

Aggressive behavior was categorized based on an adapted version of the Overt Aggression Scale (OAS; Yudofsky, Silver, Jackson, Endicott, \& Williams, 1986). The guards indicated on 8-point scales ranging from 0 (not at all) to 7 (very often) how often aggressive behavior had been shown by the inmates. The used scale is subdivided into four different kinds of aggressive behavior: Verbal aggression ('shouts angrily, curses mildly, or makes personal insults', 'curses viciously, is severely insulting, has temper outbursts', 'impulsively threatens violence toward others or self', 'rang the bell to provoke the guards'), physical aggression against self ('punched head, fist/hand, or the whole body against the floor, the wall, or against objects', 'garbled oneself, cut oneself, bit oneself until it started to bleed, caused oneself inner injuries, fractures, unconsciousness, or loss of teeth'), physical aggression against objects ('scattered clothes or made a mess', 'threw objects against the wall or the floor', 'spread the wall with food or feces', 
'destroyed objects', 'defecated into the cell'), and physical aggression against other people ('gesticulated threateningly, reached at the guards' clothes', 'attacked the guards giving them mild or moderate injuries', 'attacked the guards and inflicted serious injuries upon them'). In addition to these categories, we assessed the category interventions of the guards ('warning of the inmate', 'applying moderate physical aggressions against the inmate', 'applying strong physical aggression against the inmate', 'calling a doctor due to injuries of the inmate', 'calling a doctor due to injuries of the guard').

\section{Further investigations}

In addition to the two aggression measures, we assessed different control variables that potentially could function as moderator variables. In detail, we assessed on open scales the reason for being arrested, the nationality, the number of previous detention stays in the past, and on a 7-point scale ranging from 1 (unpleasant) to 7 (pleasant) the pleasantness in the daily contact with the inmate.

\section{Results}

\section{Aggression level}

To test whether pink prison cells lead to stronger reduction in aggression a 2 (Color: white vs. pink) $\times 2$ (Measurement time: before entering detention cell vs. after three days) analysis of variance (ANOVA) was conducted. Color was a between-participant and measurement time a within-participant factor. The ANOVA yielded only a significant main effect for measurement time, $F(1,56)=88.32, p<.001, \eta_{p}^{2}=.61$, indicating that inmates were perceived as more aggressive before entering the detention cell $(M=3.53, S D=1.47)$ than after having spent three days in the detention cell $(M=2.16, S D=1.14)$. Crucially for the hypothesis, however, neither the main effect for color, $F(1,56)=1.29, p=.26, \eta_{p}^{2}=.01$, nor the interaction between color and measurement time, $F(1,56)=.73, p=.40, \eta_{p}^{2}=.02$, was significant. Also, when only testing at the second measurement time for a difference between pink and white detention cells, no significant result could be found, $t(57)=.85, p=.44$.

\section{Aggressive behavior}

In a second analysis we tested whether the different prison cells had an effect on inmates' aggressive behavior, assessed with the OAS (Yudofsky et al., 1986). Significant differences between the cells could neither be found for the sum of all aggressive behaviors, $t(57)=1.13, p=.26\left(M_{\text {pink }}=0.57, S D=1.03 ; M_{\text {white }}=1.32, S D=3.36\right)$, nor for any aggressive sub-behaviors, $t(57)<1.05, p>.29$ (see also Table 2).

\section{Additional analyses}

To test other potential data patterns and potential moderators, we separately included several further variables as covariates in multiple analyses of covariance (ANCOVAs). That is in each ANCOVA one additional variable was included.

\section{Aggression level}

When analyzing the impact of color on rated aggression level, neither age, nationality, reason for detention, number of detention stays in the past, nor pleasantness in the daily contact with the inmate resulted in any significant effect, $F_{\mathrm{s}}<1.12, p>.33$. 
Table 2. Summary of the main results.

\begin{tabular}{|c|c|c|c|c|}
\hline & $\begin{array}{l}\text { White cell } \\
\quad(n=31)\end{array}$ & $\begin{array}{l}\text { Pink cell } \\
(n=28)\end{array}$ & & \\
\hline Assessed aggression & $M(S D)$ & $M(S D)$ & $t(57)$ & $p$ \\
\hline $\begin{array}{l}\text { Difference in rated aggression level between measurement } \\
\text { time } 1 \text { (before entering detention cell) and measurement } \\
\text { time } 2 \text { (after three days in detention cell) }\end{array}$ & $1.25(0.99)$ & $1.50(1.23)$ & -.85 & .39 \\
\hline Verbal aggression $\left(X_{1}\right)$ & $0.74(1.26)$ & $0.46(0.64)$ & 1.05 & .30 \\
\hline Physical aggression $\left(X_{2}\right)^{\mathrm{a}}$ & $0.06(0.35)$ & $0.00(0.00)$ & .95 & .35 \\
\hline Interventions of guards $\left(X_{3}\right)$ & $0.32(1.08)$ & $0.11(0.57)$ & .95 & .35 \\
\hline Sum of aggressive behavior $\left(\Sigma=X_{1}+X_{2}+X_{3}\right)$ & $1.32(3.36)$ & $0.57(1.03)$ & 1.13 & .26 \\
\hline
\end{tabular}

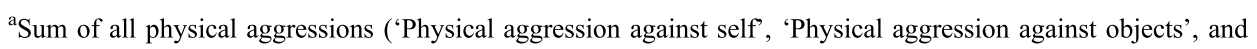
'Physical aggression against other people').

\section{Aggressive behavior}

Similar to the analyses of the aggression level, when analyzing the impact of color on actual aggressive behavior, neither age, nationality, reason for detention, number of previous detention stays in the past, pleasantness in the daily contact with the inmate, nor aggression level before entering the cell resulted in any significant result, $F_{\mathrm{s}}<1.18$, $p>.19$.

\section{Discussion}

In contrast to the early studies that often did not meet (high) methodological standards (e.g., Schauss, 1979; Pellegrini et al., 1981), in a highly standardized and controlled experiment, we did not find any differences between white and Baker-Miller pink painted prison cells in respect to rated aggressive level and actual aggressive behavior. Also, when testing several potential covariates no significant effects could be found. This might be due to different reasons. First, one may argue that the questionnaire did not accurately measure aggression. However, the relatively high Cronbach's alpha values and the fact that the questionnaires captured the decrease of aggression over the three days the inmates spent in the detention cell indicates that the questionnaire was at least adequate in validity. Moreover, the questionnaire training before the beginning of the actual study ensured the guards' calibration and accurate ratings.

Second, it might be that due to a floor effect, no differences emerged. That is, inmates' aggression level might have been already so low when entering the detention cell that no additional reduction could be achieved. However, when taking into consideration that across the two colored cells differences between the two measurement times could be detected, an effect of the color pink should have also been found if the color pink indeed would reduce aggression. Moreover, even when adding the base level of aggression into the design of the behavior analysis, no effect could be detected: Neither for inmates with a low base level of aggression nor for inmates with a high base level of aggression an effect emerged.

Third, although we find no support for the effectiveness of Baker-Miller pink on inmates' aggression reduction, it might still be that the color pink has the potential to reduce aggressive behavior, but, due to low power in our study, we were not able to 
detect such an effect. With more subjects participating in our study, we may have found support for the aggression reducing effect of the color pink. However, it is important to note that such an effect would be very small and if such a very small effect actually would exist, it opens the question of whether it is actually worthwhile to paint prison cells in pink color.

Going one step further one could speculate whether pink detention cells may even have negative (psychological) effects. Past research has indicated that the color pink is mainly associated with girls and women (Alexander, 2003; Bridges, 1993) and more preferred by girls and women than by men (Chiu et al., 2006). Being placed in a pink detention cell may thus attack inmates' perceived manhood and/or cause feelings of humiliation. At present, it is an open question what inmates actually feel and perceive when being placed into a pink detention cell and whether pink color can have negative effects under certain circumstances. Shedding more light onto the inmates' inner states may thus be an interesting question for future research.

In sum, our results rather speak against an aggression reducing impact of the color pink. This finding is especially important as earlier studies that emphasize an aggression reducing effect of the color pink (Schauss, 1979; Pellegrini et al., 1981) suffer from methodological shortcomings, but nevertheless inspired many prisons to paint their cells in pink color. Our investigations question this recent development.

\section{Acknowledgments}

We would like to thank Judith Tonner for her help in preparing the experiment, the Justizvollzugsanstalt Pöschwies for their constructive collaboration, and Zachary Langford for his proofreading.

\section{Note}

1. Unfortunately we were not able to retrieve the cited references to evaluate this evidence ourselves.

\section{References}

Alexander, G. M. (2003). An evolutionary perspective of sex-typed toy preferences: Pink, blue, and the brain. Archives of Sexual Behavior, 32(1), 7-14. doi:10.1023/A:1021833110722

Bridges, J. S. (1993). Pink or blue. Gender-stereotypic perceptions of infants as conveyed by birth congratulations cards. Psychology of Women Quarterly, 17, 193-205. doi:10.1111/j.14716402.1993.tb00444.x

Campbell, D. T., Stanley, J. C., \& Gage, N. L. (1963). Experimental and quasi-experimental designs for research. Boston, MA: Houghton Mifflin.

Chiu, S. W., Gervan, S., Fairbrother, C., Johnson, L. L., Owen-Anderson, A. F. H., Bradley, S. J., \& Zucker, K. J. (2006). Sex-dimorphic color preference in children with gender identity disorder: A comparison to clinical and community controls. Sex Roles, 55, 385-395. doi:10.1007/s11199006-9089-9

Fisher, R. A. (1935). The design of experiments. Edinburgh: Oliver \& Boyd.

Gilliam, G., \& Unruh, D. (1988). The effects of Baker-Miller pink on biological, physical and cognitive behaviors. Journal of Orthomolecular Medicine, 5, 202-206.

McDonald, J. R. (1981). The pink room: A color and aggression study in a correctional environment. Journal of Behavioral Ecology.

Ott, J. (1979). The dual function of the eyes. Southern Journal of Optometry, 21, 8-13.

Pellegrini, R. J., \& Schauss, A. G. (1980). Muscle strength as a function of exposure to hue differences in visual stimuli: An experimental test of the kinesoid hypothesis. Journal of Orthomolecular Psychiatry, 9, 144-147. 
Pellegrini, R. J., Schauss, A. G., \& Birk, T. J. (1980). Leg strength as a function of exposure to visual stimuli of different hues. Bulletin of the Psychonomic Society, 16(2), 111-112. doi:10.3758/BF03334453

Pellegrini, R. J., Schauss, A. G., Kerr, T. J., \& You, B. K. A. (1981). Grip strength and exposure to hue differences in visual stimuli: Is postural status a factor? Bulletin of the Psychonomic Society, 17(1), 27-28. doi:10.3758/BF03333657

Pellegrini, R. J., Schauss, A. G., \& Miller, M. E. (1981). Room color and aggression in a criminal detention holding cell: A test of the "tranquilizing pink" hypothesis. Journal of Othomolecular Psychiatry, 10, 174-181.

Schauss, A. G. (1979). Tranquilizing effect of color reduces aggressive behavior and potential violence. Journal of Orthomolecular Psychiatry, 8, 218-221.

Schauss, A. G. (1981). Diet, crime and delinquency. Berkeley, CA: Parker House.

Schwartz, P., Harrop, P., Love, T., Marchand, J., \& Read, C. (1983). The color pink and muscle strength. The New Zealand Medical Journal, 96, 740-741.

Snyder, M. (1981). A nursing study on the effect of environmental color on behavior. Journal of Behavioral Ecology, 2, 1-8.

Wechsler, D. (1981). Wechsler Adult Intelligence Scale - Revised. New York: The Physiological Corporation.

Yudofsky, S. C., Silver, J. M., Jackson, W., Endicott, J., \& Williams, D. (1986). The Overt Aggression Scale for the objective rating of verbal and physical aggression. The American Journal of Psychiatry, 143, 35-39. 